\title{
LETTERS
}

\section{Optic neuropathy in Wernicke encephalopathy: More than meets the eye?}

Wernicke encephalopathy is an easily missed but highly treatable condition, as the case by Drs. Fujikawa and Sogabe reminds us. ${ }^{1}$ In addition to typical features of nystagmus, ophthalmoplegia, ataxia and mental status changes, their patient had optic disc edema, which the authors felt was due to optic neuropathy unrelated to Wernicke encephalopathy. However, optic neuropathy has been described in the literature as a manifestation of thiamine deficiency, albeit uncommon, with optic disc edema present in most of these cases. $^{2-8}$ This edema seems to range from peripapillary retinal nerve fibre layer thickening with retinal hemorrhage ${ }^{2}$ to marked optic disc swelling with peripapillary hemorrhage ${ }^{3}$ to pale edema. ${ }^{4}$ In some cases, the vision loss has been severe, including loss of light perception; however, substantial visual improvement as well as resolution of edema has been reported following thiamine replacement. ${ }^{8}$ Therefore, it may be unnecessary to consider another etiology when encountering optic disc edema in a patient with Wernicke encephalopathy, particularly in the absence of other concerning neurologic or neuroimaging findings or exposures. That being said, patients with certain genetic conditions, such as Leber hereditary optic neuropathy (Leber being less likely in Drs. Fujikawa's and Sogabe's female patient), appear more vulnerable to having their optic neuropathy triggered or exacerbated by nutritional deficiencies. ${ }^{9}$

\section{Aravind Ganesh MD}

Neurology resident, Department of Clinical Neurosciences, University of Calgary, Calgary, Alta.; associate fellow, Centre for Prevention of Stroke and Dementia, University of Oxford,

Oxford, UK

\section{Malavika Varma MBBS}

Clinical director, Advanced Health

Analytics (AHA Health Ltd.), Calgary, Alta.

Cite as: CMAJ 2020 April 14;192:E409. doi: $10.1503 / \mathrm{cmaj} .74918$

\section{References}

1. Fujikawa T, Sogabe Y. Wernicke encephalopathy. CMAJ 2020;192:E143.

2. Bohnsack BL, Patel SS. Peripapillary nerve fiber layer thickening, telangiectasia, and retinal hemorrhages in Wernicke encephalopathy. $J$ Neuroophthalmol 2010;30:54-8.

3. Kulkarni S, Lee AG, Holstein SA, et al. You are what you eat. Surv Ophthalmol 2005;50:389-93.

4. van Noort BA, Bos PJ, Klopping C, et al. Optic neuropathy from thiamine deficiency in a patient with ulcerative colitis. Doc Ophthalmol 1987;67: 45-51.

5. Spinazzi M, Angelini C, Patrini C. Subacute sensory ataxia and optic neuropathy with thiamine deficiency. Nat Rev Neurol 2010;6:288-93.

6. Yeh WY, Lian LM, Chang A, et al. Thiamine-deficient optic neuropathy associated with Wernicke's encephalopathy in patients with chronic diarrhea. J Formos Med Assoc 2013;112:165-70.

7. Sechi G, Serra A. Wernicke's encephalopathy: new clinical settings and recent advances in diagnosis and management. Lancet Neurol 2007;6:442-55.

8. Gratton SM, Lam BL. Visual loss and optic nerve head swelling in thiamine deficiency without prolonged dietary deficiency. Clin Ophthalmol 2014;8:1021-4.

9. Li JM, Rucker JC. Irreversible optic neuropathy in Wernicke encephalopathy and Leber hereditary optic neuropathy. J Neuroophthalmol 2010;30: 49-53.

Competing interests: None declared. 